\title{
Comparing anterior cervical fusion using titanium cage with hydroxyapatite and with autograft
}

\author{
Prakit Tienboon ${ }^{\mathrm{a}}$, Surapon Atiprayoon ${ }^{\mathrm{b}}$ \\ ${ }^{a}$ Department of Orthopedics, Faculty of Medicine, Chulalongkorn University, Bangkok 10330; \\ ${ }^{b}$ Department of Orthopedic Surgery, Queen Savang Vadhana Memorial Hospital, Chonburi 20000, \\ Thailand
}

\begin{abstract}
Background: Anterior cervical discectomy and fusion using autogenous iliac bone graft may lead to donor site pain. This has led some surgeons to use hydroxyapatite but it has greater rates of complications.

Objective: Analyze results of the treatment of cervical spine spondylosis by anterior cervical discectomy, and to compare fusion using titanium cage with hydroxyapatite and with autograft.

Methods: We evaluated eighty patients (at 146 cervical levels) that had been treated by anterior cervical discectomy and fusion with hydroxyapatite or autograft. In a prospective study, patients were divided into two groups: 1) 77 levels of anterior cervical fusion from in 40 patients who were treated with cage and hydroxyapatite, and 2) 69 levels of anterior cervical fusions in 40 patients who were treated with cage and autograft. Results were evaluated using the Japanese Orthopedic Association (JOA) scoring system before and after surgery, subsidence, non-union and complication.

Results: According to JOA score, the first group (hydroxyapatite) had improved from 9.8 preoperation to 14.5 postoperation. The subsidence rate was $26.0 \%$, the non-union rate was $10.4 \%$, and there was no intra and post-operative complication. In the other group (autograft), the preoperative JOA score had improved from 9.3 to 14.1. The subsidence rate was $11.6 \%$, and there were no non-union and complications. Statistical significance was found in non-union and subsidence aspect between groups, but the clinical outcome of JOA score was not significantly different.
\end{abstract}

Conclusion: Anterior cervical discectomy and fusion in cervical spondylosis patients, titanium cage implantation with hydroxyapatite is a highly useful alternative to autograft.

Keywords: Anterior cervical fusion, autograft, hydroxyapatite, titanium cage

Anterior cervical fusion is proven for treatment of cervical spondylosis. The anterior approach allows direct visualization of the entire disc space and wide decompression of the anterior aspect to spinal cord and nerve roots. Some surgeons prefer to use an anterior plate to enhance stabilizing properties. However, the application of these plates is a timeconsuming procedure, and may lead to post-operative complications [1]. Recently, anterior cervical fusion with cages has become more popular. There were many reports on the primary stabilizing effects of the different cervical cages. The aim of using a cervical

Correspondence to: Assoc Prof. Prakit Tienboon, Department of Orthopedics, Faculty of Medicine, Chulalongkorn University, Bangkok 10330, Thailand. E-mail: drprakit@hotmail.com. cage in anterior cervical fusion was to provide immediate biomechanical support, to restore foraminal height, to maintain cervical lordosis and to allow optimum interverebral arthrodesis.

Autograft is the most commonly used fusion material. It is both osteoconductive and osteoinductive and produces a reliable rate of fusion [2]. However, donor site pain is a major concern [3]. The use of hydroxyapatite bone substitute was an effort to reduced donor site related complications and shorten hospital stays. Some authors recommended the use of anterior cervical fusion with cage containing bone substitutes. Although fusion was delayed compared with that in a cage containing autografts, satisfactory results were obtained regarding the fusion rates. In this study, we made prospective approach to assess 
our long-term results, subsidence rate, non-union rate, and complications of implanting interbody fusion titanium cages containing hydroxyapatite, compared to cages containing bone autograft for the treatment of cervical spondyloradiculopathy or spondylomyelopathy.

\section{Materials and methods}

One hundred forty six levels of anterior cervical fusion were performed in 80 patients for symptomatic cervical spondyloradiculopathy or spondylomyelopathy between 2004 and 2008 by two surgeons. In the prospective study, patients were divided into two groups. In the first group, there were 77 levels of anterior cervical fusion from among 40 patients who were fused with titanium cage and hydroxyapatite. The second group contained 69 levels of anterior cervical fusion from among patients who were fused with titanium cage and autograft. For the first group, the number of male and female patients with cage and hydroxyapatite was $21 / 19$, and the mean age was 59.4 years. The second group of patients was fusion with cage and autograft, had a male/female ratio of $27 / 13$ and the mean age was 50.5 years. In patients whose fusion with cage and hydroxyapatite, the diagnosis of cervical spondyloradiculopathy was $45.0 \%$ and cervical spondylomyelopathy was
$55.0 \%$. Compared to the other group whith fusion with cage and autograft, the diagnosis of cervical spondyloradiculopathy was $57.5 \%$, and cervical spondylomyelopathy was $42.5 \%$. The number of levels and the operative level are shown in Table 1.

All patients had been treated by medication and physical therapy for more than three months, but symptoms and signs did not improve. Patients with history of trauma, infection, neoplasm and rheumatoid arthritis and previous cervical spine surgery were excluded. The neurological examination and neurologic function were assessed by using the Japanese Orthopedic Association (JOA) scoring system before and after surgery in each patient. Clinical and anteroposterior and lateral radiographs were performed at one, three, six, and 12 months follow-up and then yearly. Union and subsidence were assessed by radiographs. The operative segment was considered fused by the presence of bony trabeculations across the graft-host interface, trabecular bridging bone formation, a hazy interface between the cage and the vertebral endplate and no change in position of the fused levels on dynamic views (flexion and extension). We defined subsidence as any settlement in disc height of at least three $\mathrm{mm}$ on radiographic images [4]. All complications were recorded.

Table 1. Demographic data.

\begin{tabular}{lllll}
\hline Patients & $\begin{array}{l}\text { Total } \\
(\mathbf{n = 8 0})\end{array}$ & $\begin{array}{l}\text { Hydroxyapatite } \\
(\mathbf{n = 4 0 )}\end{array}$ & $\begin{array}{l}\text { Bone graft } \\
(\mathbf{n = 4 0 )}\end{array}$ & $\begin{array}{l}\text { P-value } \\
\text { (Pearson Chi-square) }\end{array}$ \\
\hline $\begin{array}{l}\text { Mean age (year) } \\
\text { Sex }\end{array}$ & $50.5 \pm 11.8$ & $59.4( \pm 11.5)$ & $50.5( \pm 11.9)$ & 0.063 \\
$\quad$ Male & $48.0(60.0 \%)$ & $21(52.5 \%)$ & $27(67.5 \%)$ & 0.171 \\
$\quad$ Female & $32(40.0 \%)$ & $19(47.5 \%)$ & $13(32.5 \%)$ & \\
Diagnosis number (\%) & & & & \\
$\quad$ Cervical & & & & \\
$\quad$ spondyloradiculopathy & $41(51.2 \%)$ & $18(45.0 \%)$ & $23(57.5 \%)$ & 0.263 \\
Cervical & $39(48.8 \%)$ & $22(55.0 \%)$ & $17(42.5 \%)$ & 0.263 \\
$\quad$ spondylomyelopathy & $33(41.3 \%)$ & $14(35.0 \%)$ & $19(47.5 \%)$ & 0.256 \\
Level (number, \%) & $28(35.0 \%)$ & $14(35.0 \%)$ & $14(35.0 \%)$ & 1.000 \\
$\quad$ One level & $17(21.3 \%)$ & $12(30.0 \%)$ & $5(12.5 \%)$ & 0.056 \\
$\quad$ Two levels & $2(2.5 \%)$ & $0(0.0 \%)$ & $2(5.0 \%)$ & 0.152 \\
Three levels & & & & \\
Four levels & 21 & $8 / 77(10.4 \%)$ & $13 / 69(18.8 \%)$ & 0.146 \\
Operation level (Number, \%) & 41 & $21 / 77(27.3 \%)$ & $20 / 69(29.0 \%)$ & 0.818 \\
$\quad$ C3-4 & 51 & $28 / 77(36.3 \%)$ & $23 / 69(33.2 \%)$ & 0.701 \\
C4-5 & 29 & $17 / 77(22.1 \%)$ & $12 / 69(17.4 \%)$ & 0.479 \\
C5-6 & 4 & $3 / 77(3.9 \%)$ & $1 / 69(1.4 \%)$ & 0.366 \\
C6-7 & & &
\end{tabular}




\section{Surgical technique}

Exposure was via a left-sided skin incision according to the Robinson and Smith technique [5]. It consisted of removing the disc, posterior longitudinal ligament, and osteophytes including some parts of the uncinate process anteriorly. In the first group, the hollow titanium cages were impacted with hydroxyapatite graft. In the second group, the titanium cages were filled with impacted cancellous chip bone graft harvested from the left anterior iliac crest. Before closing the wound, a lateral fluoroscopic image was obtained and the correct position of the implant checked. Postoperatively, patients were allowed to mobilize freely without any support. However, those with three or four levels of fusion or aged patient were advised to wear a soft collar for a few weeks.

\section{Results}

Radiculopathy, myelopathy, and neck pain had improved in most patients. According to the JOA score, the first group improved from 9.8 pre-operatively to 14.5 pre-operatively, the subsidence rate was $26.0 \%$, the non-union rate was $10.4 \%$, and there was no complication. In the other group, the pre-operative score had improved from 9.3 to 14.1, the subsidence rate was $11.6 \%$, there was no non-union and no complication (see Fig. 1-A, 1-B). Statistical significance (Pearson Chi-square test, $\mathrm{p}<0.05$ ) existed between non-union and subsidence groups. No statistical significance was observed in JOA score and complications (Table 2). There were no reoperation, no graft complications including collapse or dislodgement, no operative site infection, no esophageal injury or related nerve injury in both groups. In the autograft group, there was little pain at donor sites and no donor site complications.

\section{Discussion}

There are several common techniques of cervical fusion. Jung et al. [6] reported cervical fusion using the polyetheretherketone (PEEK) cage containing a bovine xenograft, with $84 \%$ good to excellent results and a subsidence rate of $8 \%$. Topuz et al. [7] showed that cervical fusion with PEEK cage packed with demineralized bone matrix had $87 \%$ good to excellent results and a non-union rate of $8.3 \%$. Klimo et al. [8] found that the use of PEEK spacer and recombinant human morphogenetic protein-2 in the cervical spine produced an $8 \%$ non-union rate and high incidence of bone in growth beyond the core of the PEEK spacer and cystic regions within the cage. Bucciero et al. [9] reported that PEEK cage-assisted anterior cervical discectomy and fusion at four levels is an effective procedure for the treatment of patients with spondylotic compression of the spinal cord and nerve roots. According to the study of Agrillo et al. [10], no instability or significant complications were observed in their patients without anterior plating, even in the two-level procedures. Bulking of the plate and irritation of soft tissue anterior to the cervical spine were also problems of concern. Fusion with interbody cages has become increasingly popular. The major benefits of using cages were that they provided immediate stability, restored foraminal height and alignment and minimized operative time. Autograft from the iliac crest and hydroxyapatite are well-known fusion materials for anterior cervical fusion, but donor site pain and poor fusion rates were the main disadvantages.

Our study was performed to evaluate the results of treatment of cervical spondylosis with anterior cervical disectomy and fusion, which provided stability by the titanium cage, and use of hydroxyapatite in comparison with autograft. Given the limitations of a nonrandomized study, we found anterior cervical discectomy and fusion with cage and bone graft to be more effective than cage with hydroxyapatite in terms of subsidence and nonunion. However, the clinical outcome by JOA score was not significantly different. The traditional source of graft material for the cage filler has been cancellous bone taken from the iliac crest, as it was both osteogenic and osteoconductive and produced a reliable rate of fusion. Donor site pain was a concern. However, our technique of taking cancellous bone graft from anterior iliac crest had little problem donor pain. In order to reduce donor site complications and operative times, many different bone graft substitutes have been investigated. However, none of these has proved to be superior to autologous bone [11]. Hydroxyapatite was an osteoconductor but lacked osteoinductive properties. Chang et al. [12] reported comparing the use of radiolucent cages containing cancellous autogenous bone graft or hydroxyapatite. There were no statistically significant differences in fusion rates. There have not been any studies to compare the use of titanium cage containing hydroxyapatite versus autograft in cervical spine fusion. Our study compared these groups and found that anterior cervical discectomy and fusion with cage and bone graft was more effective than cage with hydroxyapatite in terms 


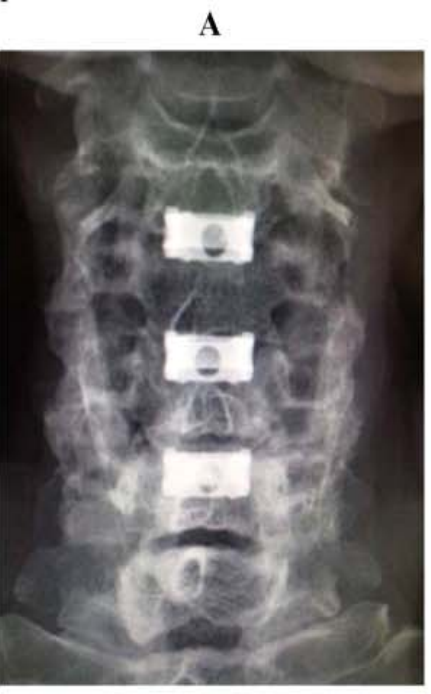

B

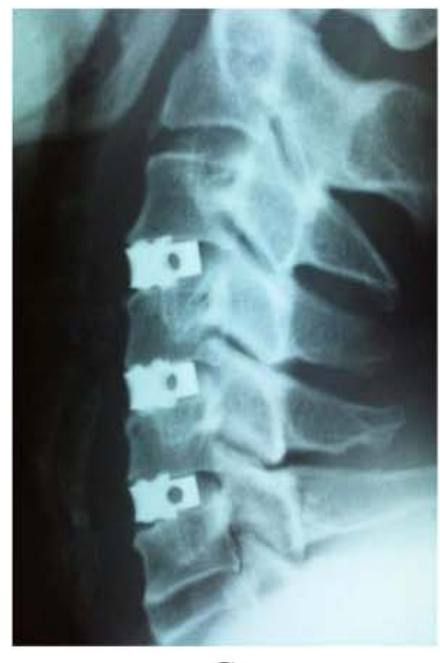

C

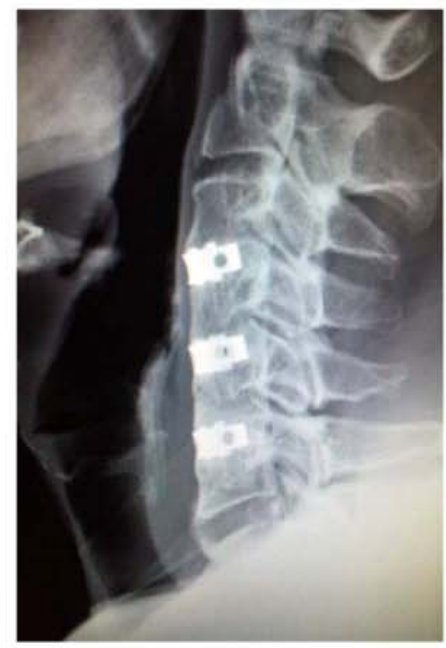

Fig. 1 A: Radiograph (anteroposterior view) of the cervical spine, showing three titanium cages with autograft inserted in place. B: Radiograph (lateral view) of cervical spine obtained at immediate postoperatively, showing cages in good position. C: Radiograph (lateral view) of the cervical spine obtained at six month postoperatively, showing solid fusion. 
Table 2. Clinical outcome.

\begin{tabular}{llll}
\hline Result & $\begin{array}{l}\text { Hydroxyapatite } \\
(\mathbf{n = 4 0 )}\end{array}$ & $\begin{array}{l}\text { Bone graft } \\
(\mathbf{n}=\mathbf{4 0})\end{array}$ & $\begin{array}{l}\text { P-value } \\
\text { (Pearson } \\
\text { Chi-square) }\end{array}$ \\
\hline $\begin{array}{l}\text { JOA score } \\
\quad \text { Pre-operation }\end{array}$ & $10.3 \pm 2.8$ & $9.3 \pm 3.7$ & 0.444 \\
$\quad \begin{array}{l}\text { Post-operation } \\
\text { Subsidence (Number, \%) }\end{array}$ & $15.0 \pm 1.9$ & $14.1 \pm 4.2$ & 0.624 \\
$\quad$ Yes & $20 / 77(26.0 \%)$ & $8 / 69(11.6 \%)$ & $0.028^{*}$ \\
$\quad$ No & $57 / 77(74.0 \%)$ & $61 / 69(88.4 \%)$ & \\
$\begin{array}{l}\text { Nonunion (Number, \%) } \\
\quad \text { Yes }\end{array}$ & $8 / 77(10.4 \%)$ & $0 / 69(0.0 \%)$ & $0.006^{*}$ \\
$\quad$ No & $69 / 77(89.6 \%)$ & $69 / 69(100.0 \%)$ & \\
Complication (Number) & 0 & 0 & \\
\hline
\end{tabular}

*Significant at level $\mathrm{p}<0.05$.

of subsidence and non-union but not significantly different in clinical outcome by JOA score. The incidence of subsidence and nonunion from hydroxyapatite group was comparable to prior reports. Hida et al. [13] reported cervical anterior fusion using titanium cage with tricalcium phosphate. The subsidence rate was $7 \%$ and non-union rate was $4 \%$. Joung et al. [14] reported that subsidence rate of cylindrical cage was $22 \%$ and there was no statistically significant difference between subsidence and clinical outcome. However in aspect of donor site pain, operative time and length of hospital stay, fusion with cage, and hydroxyapatite was better than the autograft group. Considering possible hardware-related complications such as subsidence and non-union, anterior cervical fusion with titanium cage with hydroxyapatite has clear advantages.

In conclusion, titanium cage implantation with hydroxyapatite is a highly useful alternative to the conventional treatment methods.

The authors have no conflict of interest to report.

\section{References}

1. Lee MJ, Bazaz R, Furey CG, et al. Influence of anterior cervical plate design on dysphagia: a 2-year prospective longitudinal follow-up study. J Spinal Disord Tech. 2005;18:406-9.

2. Fowler SB, Anthony-Phillips P, Metha D, Liebman K. Health-related quality of life in patients undergoing anterior cervical discectomy fusion. J Neurosci Nurs. 2005;37:97-100.

3. Silber JS, Anderson DG, Daffner SD, Brislin BT, Leland
JM, Hilibrand AS, et al. Donor site morbidity after anterior iliac crest bone harvest for single-level anterior cervical discectomy and fusion. Spine. 2003; 28:134-9.

4. Jonbergen HP, Spruit M, Anderson PG, Pavlov PW. Anterior cervical interbody fusion with a titanium box cage: early radiological assessment of fusion and subsidence. Spine J. 2005; 5:645-9.

5. Robinson RA, Smith GW. Anterolateral cervical disc removal and interbody fusion for cervical disc syndrome. Bull Johns Hopkins Hosp. 1955; 6:22-4.

6. Jung CC, Jie KY, Feng CY, Rau G, Hwei TY. Anterior cervical fusion using a polyetherterketone cage containing a bovine xenograft. Spine. 2008; 33:2524-8.

7. Topuz K, Colak A, Kaya S. Two level contiguous cervical disc diseases treated with PEEK cages packed with demineralized bone matrix: results of 3 year follow up. Eur Spine J. 2009; 18:238-43.

8. Klimo P, Peelle MW. Use of polyetherterketone spacer and recombinant human bone morphogenetic protein2 in the cervical spine: a radiographic analysis. Spine J. 2009; in press.

9. Brucciero A, Zorzi T, Piscopo GA. Peek cage-assisted anterior cervical discectomy and fusion at four levels: clinical and radiographic results. J Neurosurg Sci. 2008; 52:37-40.

10. Agrillo U, Mastronardi L, Puzzilli F. Anterior cervical fusion with carbon fiber cage containing coralline hydroxyapatite: preliminary observations in 45 consecutive cases of soft-disc herniation. J Neurosurg. 2002; 96:273-6.

11. Wigfield CC, Nelson RJ. Nonautologous interbody fusion materials in cervical spine surgery: how strong is the evidence to justify their use? Spine. 2001; 26: 
687-94.

12. Chang WC, Tsou HK. Preliminary comparison of radiolucent cages containing either autogenous cancellous bone or hydroxyapatite graft in multilevel cervical fusion. J Clin Neurosci. 2009; 16:793-6.

13. Hida K, Iwasaki Y, Akino M, Seki T. Long-term followup results in patients with cervical disk disease treated by cervical anterior fusion using titanium cage implants. Neurol Med Chir. 2008; 48:440-6.

14. Joung YI, Hoon S, Ko Y, Lee SK. Subsidence of cylindrical cage: postoperative 1 year follow-up of the cervical anterioir interbody fusion. J Korean Neurosurg Soc. 2007; 42:367-70. 